5 Creel DJ, Bendel CM, Wiesner GL, Wirtschafter JD, Arthur DC, King RA. Abnormalities of the central visual pathways in Prader-Willi syndrome associated with hypopigmentation. $N$ Engl J Med 1986;314:1606-9.

6 Frenk E, Calame A. Hypopigmentation oculocutanée familiale à transmission dominante due à un trouble de la formation des melanosones. Association d'un syndrome de Prader-Willi et d'une anomalie chromosomique chez un des sujets atteints. Schweiz Med Wochenschr 1977;107:1964-8.
${ }^{7}$ Phelan MC, Albiez KL, Flannery DB, Stevenson RE. The Prader-Willi syndrome and albinism in a black infant. Proc Greenwood Genetics Center 1988;7:27-9.

Correspondence to Dr C E Wallis, Department of Human Genetics, Medical School, University of Cape Town, Observatory 7925, South Africa.

\title{
A new recessive syndrome of unusual facies, digital abnormalities, and ichthyosis
}

\author{
JILL CLAYTON-SMITH AND DIAN DONNAI \\ Department of Medical Genetics, St Mary's Hospital, Manchester M13 0JH.
}

SUMmary Two sibs with a similar pattern of unusual facial features, limb malformations, and postnatal onset of ichthyosis are reported. The parents are first cousins and neither shows any stigmata of the disorder. The presence of ichthyosis suggests that there may be a metabolic component to this syndrome. In view of the consanguinity and pattern of the malformations, autosomal recessive inheritance seems likely.

In communities where consanguinity is common there is an increased incidence of autosomal recessive disorders, some of which are provisionally 'private' syndromes. We describe a family where a male infant was born with multiple symmetrical malformations, those in the limbs affecting the middle rays more than the outer rays. Chromosome analysis was normal and autosomal recessive inheritance was suggested to the parents, who were consanguineous. They went on to have two normal children, followed by a daughter with a similar pattern of malformations. Both affected children failed to thrive and died in infancy. The features of this syndrome are reported here for the first time.

\section{Case reports}

CASE 1

This male infant was the second child born to healthy Pakistani parents who are first cousins. The mother was 24 years old and the father 46 years. Their first child was a healthy female and the father has four healthy children from a previous marriage. The patient was born in 1984 by normal vaginal delivery at term after an uneventful pregnancy. Birth weight was $2550 \mathrm{~g}$ (3rd to 10th centile), length $50 \mathrm{~cm}$ (50th centile), and OFC $31.9 \mathrm{~cm}$ (10th to 25 th centile). He was noted to have unusual facial features at birth with bilateral inner epicanthic folds,

Received for publication 3 September 1988.

Revised version accepted for publication 11 November 1988. short forehead, and fullness of the lateral part of the eyelid. He had a small mouth with a thin upper lip and a midline groove in the lower lip. He tended to suck his lips inwards (fig 1). He had a short neck with redundant skin posteriorly and a prominent ear

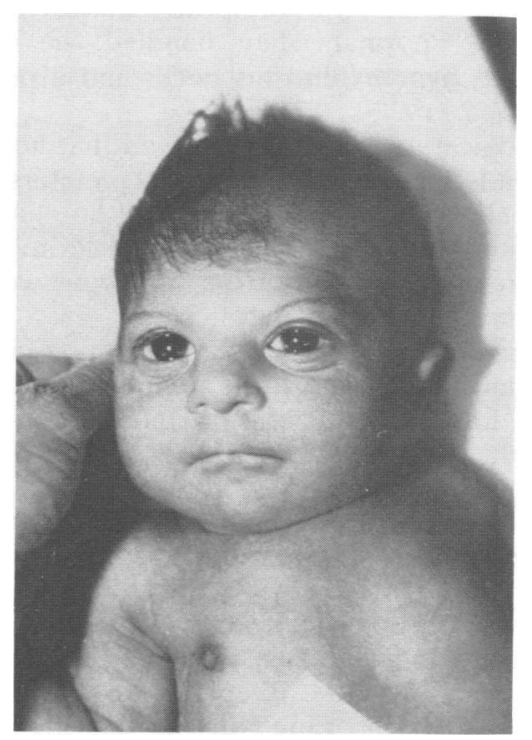

FIG 1 Case 1 aged two weeks. Note the thin upper lip, the midline groove in the lower lip, and fullness of the lateral part of the eyelid. 


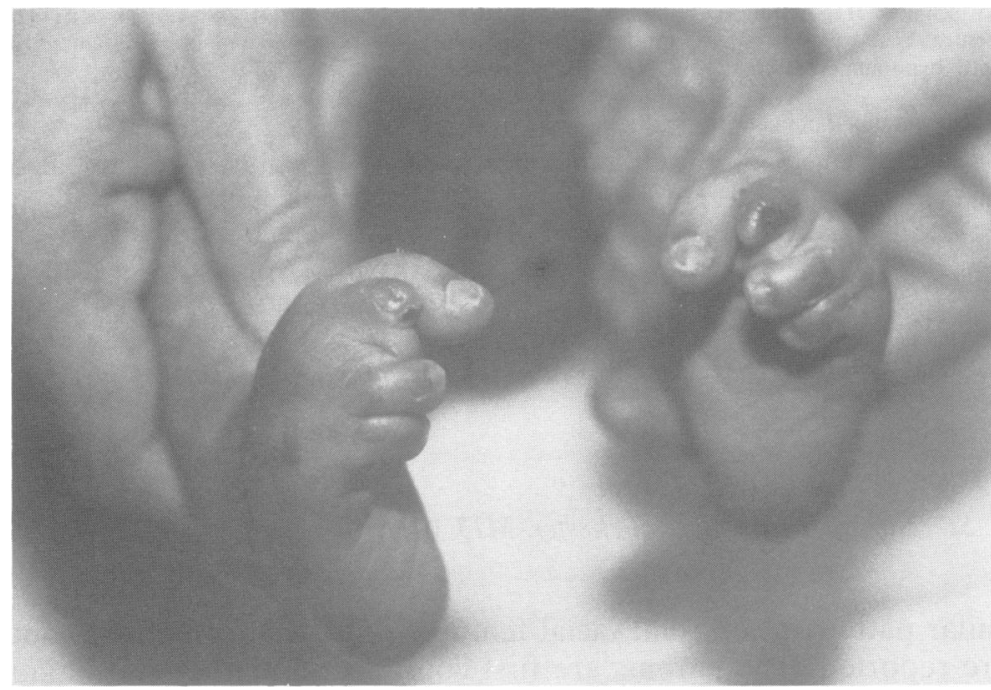

FIG 2 Case 1. The second and third toes are hypoplastic and the toes are held in fixed flexion.

crus. In the hands there was marked tapering of the fingers. The index finger was held in fixed flexion at the proximal interphalangeal joint and lacked a distal flexion crease. Both hands had single palmar creases. The elbows and knees had fixed flexion deformities and there were pigmented dimples over both patellae. The second and third toes on each foot were hypoplastic (fig 2). The other toes were held in fixed flexion. Both ankles were dislocatable. The external genitalia were normal male. The baby did not feel normal when handled, he had a tendency to hyperextend his neck, and a peculiar high pitched cry.

Radiological investigations showed that he had a prominent left sided aortic arch. The metatarsal and metacarpal bones appeared thin and the phalanges were hypoplastic. Extensive biochemical investigations were performed and the following were all normal; urea and electrolytes, blood gases, serum lead, copper, and magnesium, mucopolysaccharides, organic acids, and urine amino acids. Serum zinc was low on one occasion but normal when rechecked. No haematological or immunological abnormalities were found. Chromosome analysis of cultured lymphocytes was normal. An EMG was performed because of persistent hypotonia and was normal.

He was reluctant to feed from birth and developed abdominal distension and bile stained vomiting after 24 hours. Rectal biopsy confirmed a diagnosis of Hirschsprung's disease and he underwent a resection of the affected bowel, which was aganglionic to the splenic flexure. Further bowel surgery was required at the age of three months and the postoperative course on each occasion was complicated by the development of aspiration pneumonia. At the age of 10 weeks he developed generalised ichthyosis which was resistant to treatment with topical preparations and dietary manipulation. Developmental milestones were delayed from birth. He smiled at the age of four months but at 17 months he was not able to sit without support or to hold an object in his hands. He vocalised but could not say any recognisable syllables.

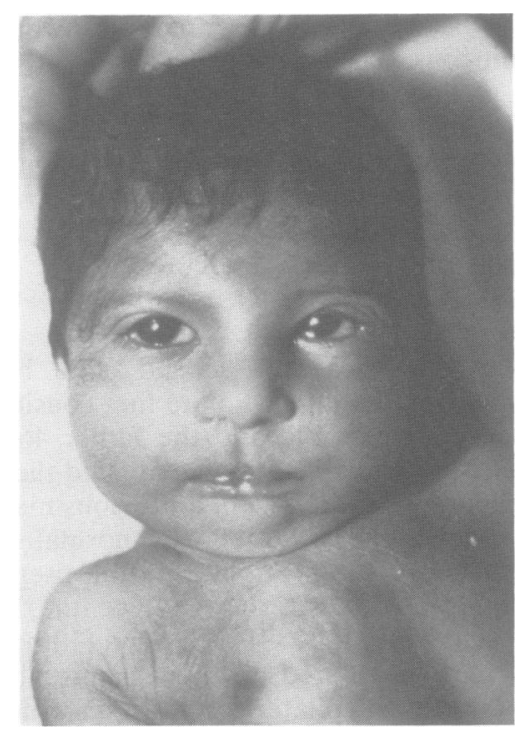

FIG 3 Case 2 at two weeks of age showing similar facial features to case 1 . 


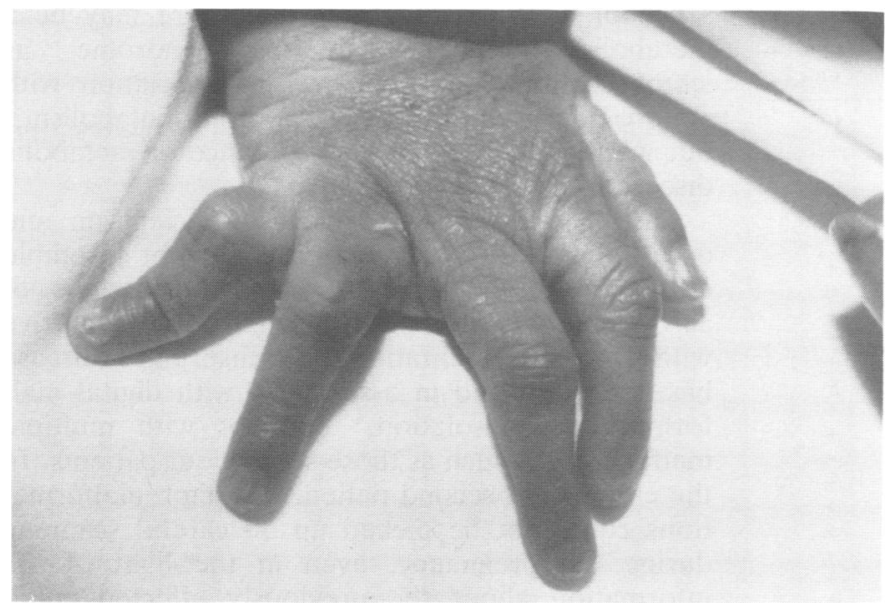

FIG 4 Case 2. The fingers are tapering and have fixed flexion deformities. The distal flexion creases were absent.

He required frequent admissions to hospital because of infections of his chest and gastrointestinal tract and for treatment of his skin condition. Growth was poor and at the age of 17 months his weight was $5.64 \mathrm{~kg}$, length $70 \mathrm{~cm}$, and OFC $41 \mathrm{~cm}$ (all <3rd centile). He was admitted to hospital at this age and died of bronchopneumonia.

\section{CASE 2}

This infant, a female born in 1987 , was the sib of case 1 . She was born at 39 weeks' gestation by normal delivery after a normal pregnancy. Birth weight was $2290 \mathrm{~g}$, length $42 \mathrm{~cm}$ and OFC $30.4 \mathrm{~cm}$ (all $<3$ rd centile). She had identical facial features to her brother (fig 3). Her mouth was small and would not open fully and she had a submucous cleft palate. Her fingers were tapering and lacked distal flexion creases (fig 4) and there was a large gap between the second and third fingers. There was redundant skin at the back of the neck and over the top part of the thoracic spine. She had a deep sacral dimple and bilateral preauricular pits (fig 5). There were fixed flexion deformities of the elbows and the ankles were dislocatable. The toenails were hypoplastic.

$X$ rays showed short metacarpals with fusion of the fourth and fifth metacarpals. The calcaneal epiphyses were small. Ultrasound scan of the head showed small irregular ventricles and scan of the renal tract showed a dilated collecting system with a thick walled bladder.

Biochemical profile and routine screening for metabolic disorders was normal. This child was slow to feed but did not have any bowel problems. She had the same high pitched cry as her affected brother and had developed generalised ichthyosis by

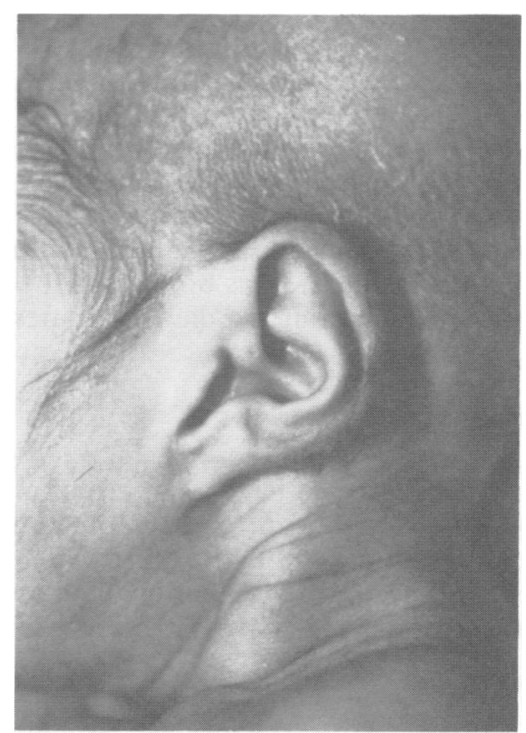

FIG 5 Case 2. Note the prominent ear crus and preauricular pit.

the age of six weeks. She was admitted to hospital at nine weeks with meningitis and after treatment she underwent exploration and closure of the sacral pit, which was found to communicate with the underlying spinal canal. At the age of four months her length, weight, and OFC remained below the third centile. She had one generalised convulsion at this time and developmental delay was already apparent. She had a tendency to regurgitate food through her nose, a problem thought to be related to her 
TABLE Features of the two sibs.

\begin{tabular}{lll}
\hline Features & Case 1 & Case 2 \\
\hline Sex & $\mathrm{M}$ & $\mathrm{F}$ \\
Birth weight below 10th centile & + & + \\
Failure to thrive & + & + \\
Epicanthic folds & + & + \\
Short forehead & + & + \\
Fullness of eyelid laterally & + & + \\
Small mouth & + & + \\
Thin upper lip & + & + \\
Midline lower lip groove & + & + \\
Submucous cleft palate & - & + \\
Redundant neck skin & + & + \\
Preauricular pits & - & + \\
Prominent ear crus & + & + \\
Sacral dimple & - & + \\
Pigmented knee dimples & + & + \\
Single palmar crease & + & + \\
Flexion deformity of PIP joint & + & + \\
Absent distal flexion crease of fingers & + & + \\
Tapering fingers & + & + \\
Hypoplastic toes and nails & + & + \\
Flexion deformity of large joints & + & + \\
Dislocatable ankles & + & + \\
Hirschsprung's disease & + & + \\
Ichthyosis & + & + \\
Developmental delay & + & + \\
High pitched cry & + & + \\
Karyotype & $+\mathrm{XY}$ & + \\
\hline
\end{tabular}

cleft palate, and she aspirated food on several occasions. She suffered from recurrent chest infections and showed profound failure to thrive. At seven months of age she was brought to the hospital in a moribund condition and died soon after arrival. No necropsy was performed.

\section{Discussion}

The two sibs described have a pattern of malformations which has not been reported previously. The features are summarised in the table. Affected male and female sibs born to consanguineous parents suggest autosomal recessive inheritance. The pre- sence of ichthyosis suggests that there may be a metabolic component to this syndrome, as ichthyosis has been reported in association with aminoaciduria ${ }^{1}$ and disorders of lipid metabolism, ${ }^{2}$ but we found no conclusive evidence of metabolic disease in either of our patients.

Case 1 was noted to be zinc deficient on one occasion but the skin condition did not resemble either in nature or distribution the lesions of acrodermatitis enteropathica ${ }^{3}$ and did not improve with zinc suplementation. Hirschsprung's disease has been reported in association with digital malformations in isolation, ${ }^{4}$ but not with multiple malformations such as those seen in our patients. In the case of the second patient, the limb malformations could not be picked up on careful scanning during the pregnancy, even in the light of the information about the previously affected child, because the appearances were too subtle. It might be possible to detect the limb malformations by fetoscopy in a subsequent pregnancy.

\section{References}

${ }^{1}$ Passwell J, Zipperkowski L, Katznelson D, et al. A syndrome characterised by congenital ichthyosis with atrophy, mental retardation, dwarfism and generalised aminoaciduria. $J$ Pediatr 1973;82:466-71.

2 Williams ML, Koch TK, O'Donnell JJ, et al. Ichthyosis and neutral lipid storage disease. Am J Med Genet 1985;20:711-26.

3 Rosenblum JL, Schweitzer J, Kissane JM, Cooper TW. Failure to thrive presenting with an unusual skin rash. $J$ Pediatr 1985;107:149-53.

4 Reynolds JF, Barber JC, Alford BA, Chandler JG, Kelly TE. Familial Hirschsprung's disease and type D brachydactyly: a report of four affected males in two generations. Pediatrics 1983;71:246-9.

Correspondence to Dr J Clayton-Smith, Department of Medical Genetics, St Mary's Hospital, Whitworth Park, Manchester M13 0JH. 